\title{
Olfactory behavior and physiology are disrupted in prion protein knockout mice
}

\author{
Claire E Le Pichon ${ }^{1}$, Matthew T Valley ${ }^{1}$, Magdalini Polymenidou ${ }^{2,3}$, Alexander T Chesler ${ }^{1}$, Botir T Sagdullaev ${ }^{1,3}$, \\ Adriano Aguzzi $^{2} \&$ Stuart Firestein ${ }^{1}$
}

\begin{abstract}
The prion protein $\mathrm{PrPC}^{\mathrm{C}}$ is infamous for its role in disease, but its normal physiological function remains unknown. Here we found a previously unknown behavioral phenotype of $\operatorname{Prnp}^{-1-}$ mice in an odor-guided task. This phenotype was manifest in three Prnp knockout lines on different genetic backgrounds, which provides strong evidence that the phenotype is caused by a lack of PrPC rather than by other genetic factors. Prnp ${ }^{-1-}$ mice also showed altered behavior in a second olfactory task, suggesting that the phenotype is olfactory specific. Furthermore, PrPC deficiency affected oscillatory activity in the deep layers of the main olfactory bulb, as well as dendrodendritic synaptic transmission between olfactory bulb granule and mitral cells. Notably, both the behavioral and electrophysiological alterations found in $\mathrm{Prnp}^{-1-}$ mice were rescued by transgenic neuronal-specific expression of PrPC. These data suggest that $\mathrm{PrP}^{\mathrm{C}}$ is important in the normal processing of sensory information by the olfactory system.
\end{abstract}

Despite two decades of research, the function of the cellular prion protein $\mathrm{PrP}^{\mathrm{C}}$ is still unknown. It had been hoped the $\mathrm{Prnp}^{-1-}$ mouse would provide evidence for the function of this protein that is so widely expressed in all vertebrates, at all stages and in almost all tissues, especially in the brain. Such ubiquity suggests that $\mathrm{PrP}^{\mathrm{C}}$ might perform some essential cellular function. However, the first $\operatorname{Prnp}^{-1-}$ mouse showed no overt phenotype, implying that the protein was dispensable ${ }^{1}$. Instead, the major finding in $\operatorname{Prnp}^{-/-}$mice was their resistance to prion disease ${ }^{2}$.

Nevertheless, it is unlikely that the PrP protein would have evolved simply to enable a rare fatal disease. Indeed, since the initial knockout mouse study, a host of subtle phenotypes have been described, ranging from behavioral changes to electrophysiological and biochemical alterations ${ }^{3}$. The reported behavioral phenotypes are of a disparate nature, as might be expected from the widespread expression pattern of $\mathrm{PrP}^{\mathrm{C}}$ in the brain. They include altered circadian rhythm ${ }^{4}$, modified sleep patterns ${ }^{5}$, impaired spatial learning behavior in the Barnes circular maze $e^{6}$ and increased sensitivity to seizure ${ }^{7,8}$.

Despite the wide gamut of behaviors that have been tested in PrP knockouts, almost all have relied on spatiovisual or vibrissotactile cues, whereas olfactory-cued tasks have, to the best of our knowledge, been overlooked. Because we and others had detected widespread $\mathrm{PrP}^{\mathrm{C}}$ expression throughout the olfactory system ${ }^{9,10}$, we reasoned that olfactory-mediated behaviors might be affected in Prnp $^{-1-}$ mice.

The sense of smell is critical to the survival of many animals, mediating essential behaviors such as feeding and mating. The basic circuit of the olfactory system in mice and other mammals, from sensory epithelium to cortex, consists of only two projection synapses (peripheral sensory neuron to mitral cell in the olfactory bulb and mitral cell to pyramidal cell in the cortex) and two layers of inhibitory lateral processing (periglomerular and granule cells) in the olfactory bulb. In particular, mitral and granule cells make a unique dendrodendritic synapse in which mitral cells excite granule cells that reciprocally inhibit the mitral cell. This inhibitory circuit is thought to be involved in synchronizing mitral cell firing and enabling lateral inhibition ${ }^{11,12}$.

Here we uncovered a previously unknown phenotype of Prnp ${ }^{-1-}$ mice in the olfactory system by using a combination of genetic, behavioral and physiological techniques in a systems approach. We employed the so-called 'cookie-finding task', a test of broad olfactory acuity, to analyze a battery of mice, including $\operatorname{PrP}^{\mathrm{C}}$ knockouts on multiple genetic backgrounds and transgenic mice in which Prnp expression was driven by cell type-specific promoters. In this test, PrP-deficient mice showed impaired behavior that was rescued in transgenic mice expressing $\operatorname{PrP}^{\mathrm{C}}$ specifically in neurons but not in mice expressing only extra-neuronal $\operatorname{PrP}^{\mathrm{C}}$. Prnp ${ }^{-1-}$ mice had altered behavior in an additional olfactory test (habituation-dishabituation), which was also rescued by transgenic neuronal PrP expression, suggesting the phenotype was olfactory specific.

With this evidence that the underlying alteration resided beyond the periphery, we investigated the odor-evoked electrophysiological properties of the olfactory bulb of PrP knockouts. In these mice, we detected alterations in the patterns of oscillatory activity in the olfactory bulb and in the plasticity of dendrodendritic synaptic transmission between granule cells and mitral cells. We propose that electrophysiological

${ }^{1}$ Department of Biological Sciences, Columbia University, 1212 Amsterdam Avenue, New York, New York 10027, USA. ${ }^{2}$ Institute of Neuropathology, University Hospital Zürich, Schmelzbergstrasse 12, 8091 Zürich, Switzerland. 3Present addresses: Ludwig Institute for Cancer Research, University of California at San Diego, 9500 Gilman Drive, La Jolla, California 92093, USA (M.P.) and Weill Medical College of Cornell University, 785 Mamaroneck Avenue, White Plains, New York 10605, USA (B.T.S.). Correspondence should be addressed to S.F. (sjf24@columbia.edu). 
Figure 1 Impaired behavior of Zürich I Prnp ${ }^{-/-}$ mice in the cookie-finding test. (a) Trial 1 of the cookie-finding test for B6129 (filled dots) and Zürich I line (ZI) Prnp $^{-1-}$ (open dots) mice. Each dot represents a single individual. Individuals that failed the trial were assigned the conservative score of $600 \mathrm{~s}$, which corresponded to the total test time. Black lines represent medians. (b) Trial 2. Note that trial times were reduced to $5 \mathrm{~min}$. Individuals that failed trial 2 were given the conservative score of 300 s. (c) Schematic diagram of the genetic makeup of the B6129 wild-type and Zürich I line Prnp ${ }^{-1-}$ mice on a mixed $\mathrm{B} 6$ and 129 background. The red cross represents the knockout allele of Prnp. The black and cyan sections represent alleles of B6 and 129 origin, respectively. (d) Individual progression of each B6129 mouse from trial 1 to trial 2 . (e) Individual progression from trial 1 to trial 2 of each Zürich I line Prnp ${ }^{-1-}$ mouse, excluding animals that failed trial 1 or that found the cookie in trial 1 with a latency greater than $300 \mathrm{~s}$ and also failed trial 2. $n$ is indicated for points that overlap exactly. (f) Average degree of improvement for wild-type (filled dots) and knockout (open dots) mice, calculated as $\sum$ (T1/ $\mathrm{T} 2) / \mathrm{n}$, excluding animals that failed to find the cookie in trial 1 or that found the cookie in trial 1 with a latency greater than $300 \mathrm{~s}$ and also failed trial 2 . Error bars represent \pm s.e.m. ${ }^{*} P<0.05$ (one-tailed unpaired $t$ test), ${ }^{* * *} P<0.001$ (two-tailed Mann-Whitney test).
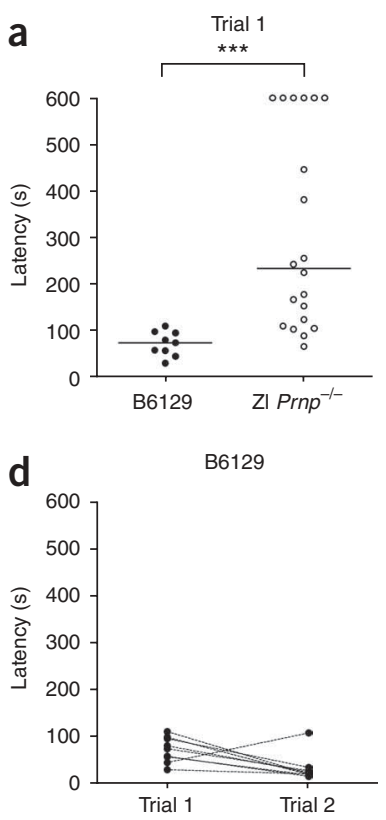

C B6129 e

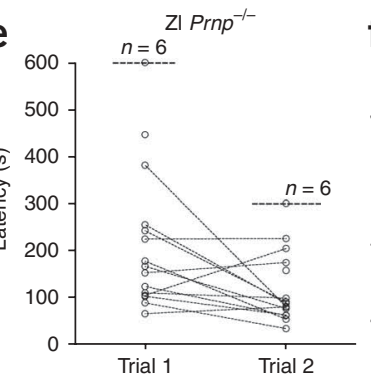

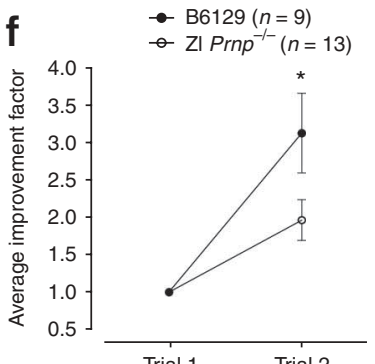

alterations at the dendrodendritic synapse in the olfactory bulb could underlie the behavioral phenotype that we found.

\section{RESULTS}

\section{Prnp $^{-1-}$ mice show altered behavior in an olfactory task}

We used a test that measures olfactory detection (cookie-finding test; Fig. 1 $)^{13}$. Mice that are faster at retrieving the cookie are thought to have a better sense of smell. The first of two successive trials reflected naive olfactory-mediated finding and the second indicated the mouse's ability to improve on the basis of positive reinforcement received in the first trial.

In trial 1, wild-type mice retrieved the cookie in a median latency time of 73 s, whereas $\operatorname{Prnp}^{-1-}$ mice (Zürich I line; Fig. 1c) were significantly slower at 233 s $(P<0.001$, Mann-Whitney test; Fig. 1a). Furthermore, close to a third of the $\operatorname{Prnp}^{-1-}$ mice (6 out of 20) failed to find the cookie in the 10-min test time, whereas no wildtype mouse failed the test.

In trial 2, $\operatorname{Prn}^{-1-}$ mice were again significantly slower than wild types at retrieving the cookie (wild-type median, $20 \mathrm{~s}$; $\mathrm{Prnp}^{-1-}$ median, 127.5 s; $P<0.001$, Mann-Whitney test; Fig. 1b). Even if those Prn $p^{-/-}$ mice that had failed Trial 1 were excluded from the analysis on the basis of their failure to have received positive reinforcement, the differences were still significant (wild-type median, $20 \mathrm{~s}$; Prnp $^{-1-}$ median, $83.5 \mathrm{~s}$; $P<0.01$ Mann-Whitney test).

The slower latencies of $\mathrm{Prnp}^{-1-}$ mice in both trials were not a result of a lack of exploration (as assessed by the number of crossings from one cage quadrant to another), a lack of appetite (as these mice readily consumed the cookie on finding it) or a metabolic alteration (all tested mice showed similar weight and daily food consumption regardless of genotype) (Supplementary Fig. 1 online and data not shown). Furthermore, the difference between $\operatorname{Prnp}^{-/-}$and wild-type mice did not result from a locomotor deficiency in the knockouts, as both performed similarly in a control version of this experiment in which the cookie was presented on the surface of the bedding instead of being buried underneath it (Supplementary Fig. 1).
Comparing trials 1 and 2, we observed that wild-type mice improved from a median of $73 \mathrm{~s}$ to $20 \mathrm{~s}$, whereas $\mathrm{Prnp}^{-/-}$mice improved, at best, from $233 \mathrm{~s}$ to $83.5 \mathrm{~s}$. Eight out of nine wild-type mice improved between trials 1 and 2 (Fig. 1d), compared with only 8 out of 13 knockouts (and excluding those that had failed trial 1 or 2 ; Fig. 1e). We calculated an improvement factor corresponding to the average ratio of the latency in trial 1 versus trial 2. Overall, wild-type mice improved threefold (3.12 \pm 0.53 s.e.m.), whereas $\operatorname{Prnp}^{-1-}$ mice only improved twofold ( $1.97 \pm 0.29$; $P<0.05$, one-tailed $t$ test). The difference in the degree of improvement was even greater considering the floor effect on wild-type latencies resulting from the initial rapidity in trial 1 . Thus, $\operatorname{Prnp}^{-/-}$mice showed impaired behavior in this odor-guided task.

\section{Prnp $^{-1-}$ mouse behavior resembles that of anosmic mice}

For comparison with a negative extreme of possible behaviors in this task, we tested a known anosmic mouse, the adenylyl cyclase type 3 (AC3) knockout $\left(A d c y 3^{--}\right)$. AC3 is a component of the olfactory transduction cascade that is necessary for generating action potentials in response to odorant binding at an odorant receptor. Adcy $3^{-/}$mice have been shown to be largely anosmic ${ }^{14}$, although they retain residual olfactory capacity via their vomeronasal organ ${ }^{15}$.

To control for the mixed genetic background of both the $\operatorname{Prnp}^{-/-}$and Adcy $3^{-1-}$ mice, we also tested both pure parental strains C57BL/6J (B6) and $129 / \mathrm{SvEv}$ (129). Because of animal availability, this experiment was conducted in a different facility, necessitating the retesting of the wildtype B6129 and Zürich I line Prnp ${ }^{-1-}$ mice for comparison with our previous results. The altered environmental conditions may explain the raw data differences for the B6129 and Prnp $^{-1-}$ mice between the two experiments (Fig. 2 versus Fig. 1).

Despite these differences, the same trend was apparent under both experimental conditions. All wild-type mice, regardless of strain, achieved much faster latencies to retrieve the cookie than either the Prnp $^{-/-}$or $A d c y 3^{-/-}$mice, a substantial proportion of which failed both trials (Fig. 2a,b). In trial 1, Prnp ${ }^{-1-}$ mice, similar to Adcy $3^{-1-}$ mice, trended toward slower latencies than wild types (wild-type medians: 

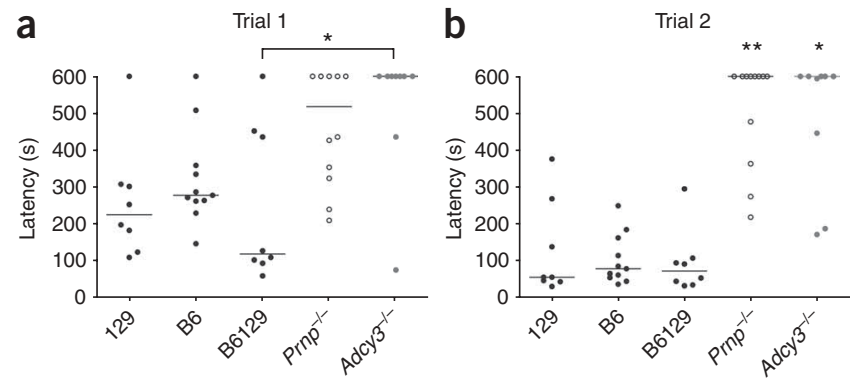

Figure 2 Zürich I Prnp ${ }^{-1-}$ mouse behavior resembles that of a known anosmic mouse $\left(A d c y 3^{--}\right)$. (a) Scatter plot showing performance of wild-type strains 129, B6 and B6129 (black dots), Zürich I line Prnp-l- (open), and Adcy3 ${ }^{-1-}$ (gray) in trial 1 of the cookie-finding test. Individuals that failed to find the cookie in the test time were assigned the conservative score of $600 \mathrm{~s}$, corresponding to the total test time. Black lines represent median values. (b) Trial 2 performances for the same mice. ${ }^{*} P<0.05$, ${ }^{* *} P<0.01$, Dunn's multiple comparison test. Note that values for B6129 wild-type and Zürich I line Prnp ${ }^{-/}$mice differ from those in Figure 1 because this test was performed under alternate experimental conditions.

$225.5 \mathrm{~s}$ (129), $278 \mathrm{~s}$ (B6) and $119 \mathrm{~s}$ (B6129); Prnp $^{-1-}$ median, $518 \mathrm{~s}$; Adcy $3^{-/-}$median, $600 \mathrm{~s}$; Fig. 2a). In trial 2, Prnp ${ }^{-/-}$mice continued to resemble $A d c y 3^{-/-}$mice, failing to improve and contrasting significantly with wild types (wild-type medians: $56 \mathrm{~s}$ (129), $79 \mathrm{~s}$ (B6) and $73 \mathrm{~s}$ (B6129 F1); Prnp ${ }^{-/-}$and Adcy $3^{-1-}$ mice, both $600 \mathrm{~s}, P<0.01$ and $\mathrm{P}<$ 0.05, respectively, Dunn's multiple comparison test; Fig. 2b).

\section{Prnp $^{-/}$phenotype extends to other genetic backgrounds}

Because the phenotypic impairment had been detected in a Prnp ${ }^{-1-}$ mouse on mixed genetic background and lacking wild-type littermates, it is possible that the phenotype that we detected was the result of a genetic factor other than the absence of $\mathrm{PrP}^{\mathrm{C}}$. We thus tested two additional Prnp ${ }^{-/}$lines (Fig. 3), one congenic with B6 (Nagasaki; Fig. 3c) and one isogenic with 129 (Edinburgh; Fig. 3i), reasoning that if the phenotype were also observable on these backgrounds, it might indeed be attributable to PrP deficiency rather than to another genetic factor.

The Nagasaki Prnp ${ }^{--}$mouse line is not usually a line of choice for phenotypic analysis of PrP deficiency, as the mice develop late-onset ataxia as a result of spurious upregulation of the downstream gene

Figure 3 The cookie-finding phenotype is manifest in Prnp knockouts on other genetic backgrounds. (a) Trial 1 of the cookie-finding test for B6 (filled) and Nagasaki (Ng) Prnp ${ }^{-1-}$ (open). (b) Trial 2 for mice shown in a. Note the reduced timescale of $5 \mathrm{~min}$. (c) Schematic diagram of genetic background of the B6 wild-type and congenic Nagasaki Prnp ${ }^{-1-}$ mice. Black and cyan sections represent alleles of $\mathrm{B} 6$ and 129 origin, respectively. The red cross represents the knockout allele. (d) Individual progression from trial 1 to trial 2 of each B6 mouse. (e) Individual progression from trial 1 to trial 2 of each Nagasaki Prnp ${ }^{-1-}$ mouse. (f) Average degree of improvement for B6 (filled) and Nagasaki Prnp ${ }^{-1-}$ (open). Error bars \pm s.e.m. (g) Trial 1 of the cookiefinding test for Edinburgh (Ed) Prnp ${ }^{+/+}$(filled) and Edinburgh Prnp ${ }^{-/}$(open) mice. (h) Trial 2 for mice shown in $\mathbf{g}$. (i) Schematic diagram of genetic background of the Edinburgh $\mathrm{Prnp}^{-1}$ and isogenic wild-type littermates (129/Ola background). Cyan sections represent alleles of 129/Ola origin. The red cross represents the knockout allele. (j) Individual progression from trial 1 to trial 2 of each 129/Ola wild-type mouse. (k) Individual progression from trial 1 to trial 2 of each Edinburgh $\mathrm{Prnp}^{-1-}$ mouse. (I) Average degrees of improvement for Edinburgh Prnp ${ }^{-/-}$(open) and Prnp ${ }^{+/+}$littermates (filled) were not significantly different because of the low $n$. Error bars \pm s.e.m. Black lines represent median values. ${ }^{*} P<0.05$ (one-tailed unpaired $t$ test), $* * * P<0.001$ (two-tailed Mann Whitney test).
$\operatorname{Prnd}^{16}$. However, these mice show no symptoms before 1 year of age, and we tested them at the presymptomatic age of 7-10 weeks, which is well before their decline (70 weeks).

We noticed an effect of a predominantly B6 genetic background on cookie-finding behavior; Nagasaki Prnp ${ }^{-1-}$ mice scored faster latencies than the Zürich I line (Nagasaki median, $155 \mathrm{~s}$; Zürich I line median, 223s). In trial 1, not a single Nagasaki $\operatorname{Prn}^{-1-}$ mouse failed to find the cookie, whereas 6 out of 20 Zürich I line $\mathrm{Prnp}^{-1-}$ mice failed (Fig. 3a versus Fig. 1a). Nevertheless, the Nagasaki knockouts were significantly slower than their wild-type counterparts (wild-type median, $76.5 \mathrm{~s}$; Prn $p^{-/-}$, median 155 s; $P<0.05$, Mann-Whitney test; Fig. 3a), thus revealing a phenotype similar to the one that we detected in the Zürich I Prnp ${ }^{-l-}$ line.

In trial 2, Nagasaki knockouts were significantly slower than their wild-type counterparts (wild-type median, $27.5 \mathrm{~s}$; $\mathrm{Prnp}^{-1-}$ median, 89.5 s; $P<0.001$, Mann-Whitney test; Fig. 3b). The fastest knockout latencies in trial 2 clustered around $62 \mathrm{~s}$, close to double the median wild-type latency (Fig. 3b). Although the knockouts tended to improve in trial 2 (Fig. 3e), they failed to improve as much as wild types (Fig. 3d). Overall, the $\operatorname{Prnp}^{-1-}$ mouse improvement was almost twofold less than wild types (wild-type improvement factor, $3.84 \pm 0.68$ s.e.m.; Prnp ${ }^{-1-}$ improvement factor, $1.96 \pm 0.32 ; P<0.05$, one-tailed unpaired $t$ test; Fig. 3f). The phenotype exhibited by Zürich I line Prnp knockouts was thus confirmed by another knockout line.

However, because of residual 129 alleles that are tightly linked to the knockout allele in the Nagasaki $\operatorname{Prnp}^{-1-}$ mouse line, which is otherwise congenic with B6, we still could not fully attribute the phenotype to the absence of PrP. We thus tested a third $\operatorname{Prnp}^{-1-}$ mouse line, the
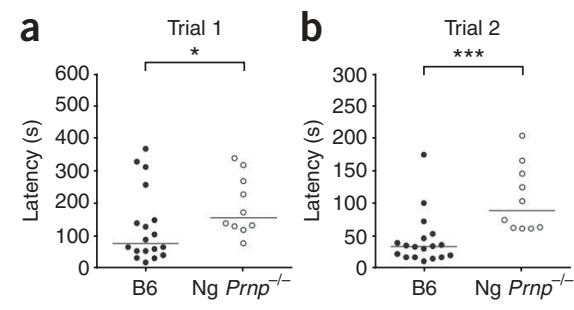

C

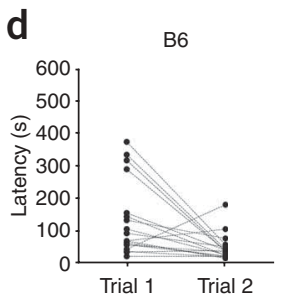

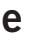
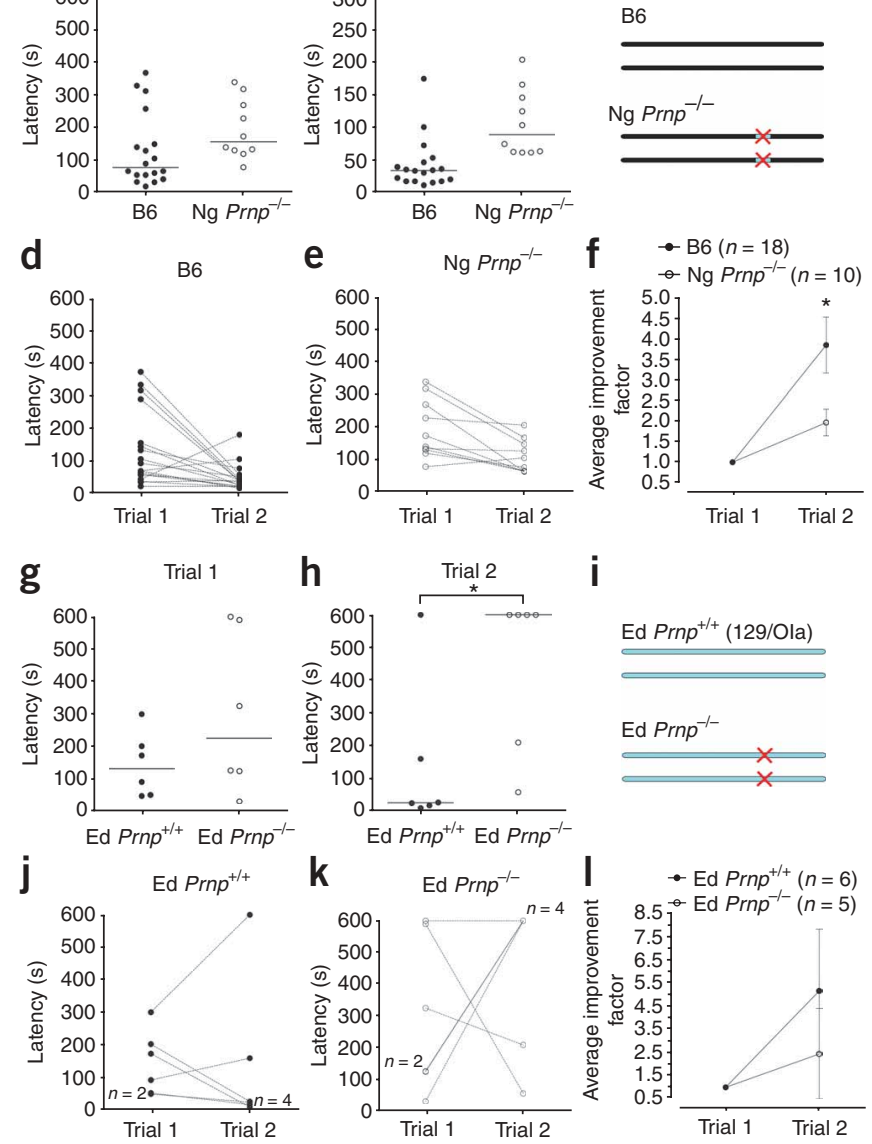

\section{i}

Ed $\operatorname{Prnp}^{+/+}(129 / \mathrm{Ola})$

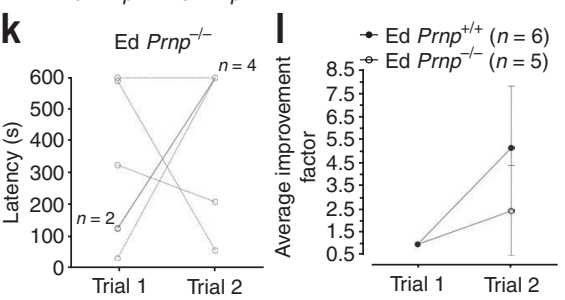


Table 1 Mouse strains tested for cookie finding behavior

\begin{tabular}{|c|c|c|c|c|c|c|}
\hline Strain name & Abbreviation & Type & Description & $\begin{array}{l}\text { Reference } \\
\text { number }\end{array}$ & Genetic background & PrPC expression \\
\hline $\begin{array}{l}\mathrm{C} 57 \mathrm{BL} / 6 \mathrm{~J} \times 129 / \mathrm{Sv} \\
\text { F1 hybrid }\end{array}$ & B6129 & Wild type & Wild-type hybrid & Methods & $\begin{array}{l}50 \% \text { C57BL/6J, } \\
50 \% 129 \mathrm{~S} / \mathrm{Sv}\end{array}$ & Wild type \\
\hline Zürich I Prnp-1- & & Knockout & Prnp knockout & 1 & $\begin{array}{l}\text { C57BL } 6 \mathrm{~J} \times 129 / \mathrm{Sv} \\
\text { mixed background }\end{array}$ & None \\
\hline Nagasaki Prnp ${ }^{-/-}$ & & Knockout & $\begin{array}{l}\text { Prnp knockout with late-onset } \\
\text { ataxia as a result of upregulation of Prnd }\end{array}$ & 42 & Congenic C57BL/6J & None \\
\hline Edinburgh Prnp ${ }^{-1-}$ & & Knockout & Prnp knockout & 38 & Isogenic 129/Ola & None \\
\hline Tg20 & Tg20 & Transgenic & $\begin{array}{l}\text { Prnp driven by endogenous } \\
\text { Prnp promoter ('half-genomic construct') }\end{array}$ & 43 & Zürich I Prnp ${ }^{-/-}$background & $\begin{array}{l}\text { Overexpression in } \\
\text { wild-type locations }\end{array}$ \\
\hline NSE-PrP & NSE-PrP & Transgenic & Prnp driven by Eno2 promoter & 44 & Zürich I Prnp ${ }^{-1-}$ background & $\begin{array}{l}\text { Neurons only (central and } \\
\text { peripheral nervous system) }\end{array}$ \\
\hline MBP-PrP & MBP-PrP & Transgenic & Prnp driven by $M b p$ promoter & 45 & Zürich I Prnp ${ }^{-1-}$ background & $\begin{array}{l}\text { Oligodendrocytes and } \\
\text { Schwann cells only }\end{array}$ \\
\hline Tg306 & CD19-PrP & Transgenic & Prnp driven by $C D 19$ promoter & 46 & Zürich I Prnp ${ }^{-1-}$ background & B cells only \\
\hline Tg33 & Lck-PrP & Transgenic & Prnp driven by Lck promoter & 47 & Zürich I Prnp ${ }^{-1-}$ background & T cells and some neurons \\
\hline Prn knockout & $\mathrm{Prn}^{-1-}$ & Knockout & $\begin{array}{l}\text { Double knockout of Prnp and } \\
\text { homologous downstream gene Prnd }\end{array}$ & 48 & $\begin{array}{l}\text { C57BL } 6 \mathrm{~J} \times 129 / \mathrm{Sv} \text { mixed } \\
\text { background }\end{array}$ & None \\
\hline
\end{tabular}

All knockout and transgenic animals presented in this table are on the Zürich I mixed B6 and 129 genetic background. Notably, the transgenic lines were generated by microinjection of Prnp transgenes into homozygous Zürich I Prnp ${ }^{-1-}$ zygotes, thus enabling direct comparisons between the different lines.

Edinburgh line, on a pure 129/Ola background. These mice are isogenic with their wild-type counterparts, thus circumventing the problem of mixed background (Fig. 3i).

On this background too the phenotype was apparent. Although $\operatorname{Prnp}^{+/+}$mice only trended toward faster latencies in trial 1 (wild-type median, 133.5 s; Prnp $^{-1-}$ median, 227 s; Fig. 3g), they were significantly faster in trial 2 (wild-type median, $26 \mathrm{~s}$; Prnp $^{-1-}$ median, $600 \mathrm{~s}$; $P<0.05$, Mann-Whitney test; Fig. 3h). In trial 2, four out of six wildtype mice improved to very fast latencies (Fig. 3j), whereas Prnp ${ }^{-/-}$ mice showed no clear trend toward improvement, with four out of six failing the trial (Fig. 3k). The average improvement factors were not significantly different as a result of the small sample size (wild type, $5.16 \pm 2.7$; Prnp $^{-/-}, 2.44 \pm 2.0$; Fig. 31).

Thus, although the severity of the phenotype varied with the genetic background, we found that $\mathrm{Prnp}^{-/-}$mice showed impaired behavior in the cookie-finding test on a mixed B6 $\times 129$, a congenic B6 and an isogenic 129/Ola background.

\section{The Prnp $^{-1-}$ phenotype is rescued by neuronal PrP expression}

We next asked whether neuronal-specific $\mathrm{PrP}^{\mathrm{C}}$ expression could selectively rescue the phenotype. We tested a battery of knockout and transgenic mice that were all on the Zürich I mixed background (Table 1 and Fig. 4). We pooled animals according to whether or not they expressed Prnp in neurons, which we confirmed by in situ hybridization, and examined whether neuronal $\operatorname{PrP}^{\mathrm{C}}$ improved cookie-finding performance. The difference between the two groups was notable. In both trials, the mice lacking neuronal $\mathrm{PrP}^{\mathrm{C}}$ were twice as slow as mice that expressed $\operatorname{PrP}^{C}$ in neurons $(P<0.001$, MannWhitney test; Fig. 4a,b).

This difference was not a result of the effect of any particular strain, as shown by separating the groups into individual datasets (Fig. 4c,d). Overexpression of $\mathrm{PrP}^{\mathrm{C}}$ on a $\mathrm{Prnp}^{-/-}$background (Tg20 mouse line) exerted a rescuing effect, as did NSE-driven expression of $\mathrm{PrPC}^{\mathrm{C}}$ (that is, neuronal-specific expression, NSE-PrP mouse line). Both these lines closely resembled the B6129 wild types (Fig. 4c,d) with trial 1 medians all being below $100 \mathrm{~s}$ and trial 2 medians being below $40 \mathrm{~s}$. In contrast, when PrP was expressed in non-neuronal cells such as myelinating glia
(MBP-PrP mouse line) or B cells (CD19-PrP mouse line), the mice were not rescued and phenotypically resembled the Zürich I line Prnp ${ }^{-1-}$ mice (Fig. 4c,d). In addition, Prnp and Prnd (a downstream gene of $\operatorname{Prnp}$ ) double-knockout mice $\left(\mathrm{Prn}^{--}\right)$were also impaired. All mice lacking neuronal $\mathrm{PrP}^{\mathrm{C}}$ showed median latencies above $160 \mathrm{~s}$ in trial 1 (Fig. 4c) and above $125 \mathrm{~s}$ in trial 2 (Fig. 4d). The case of the LckPrP mouse line (Fig. 4c,d) will be discussed below.

\section{Lck-PrP mice express neuronal Prnp in the olfactory bulb}

Notably, the Lck-PrP transgenic line (Fig. 4c,d) appeared to be at least partially rescued by its particular pattern of PrP expression. Lck encodes lymphocyte protein tyrosine kinase and is highly expressed in T cells. By in situ hybridization, however, we found that the Lck promoter drove Prnp expression in several brain areas (Fig. 5), including the olfactory bulb (in juxtaglomerular cells, mitral/tufted cells and granule cells; Fig. 5a) and the cerebellum (Fig. 5b). In contrast, CD19-PrP mice (B cell-specific expressers) showed no such staining (Fig. 5d). Other reports have also detected an active Lck promoter in neurons of the brain, including in olfactory areas ${ }^{17}$ (Allen Brain Atlas, http://www.brain-map.org/).

We excluded the Lck-PrP line from the groups listed above (Fig. 4a,b), as $\operatorname{PrP}^{\mathrm{C}}$ was expressed in some, but not all, neurons in these mice. However, the substantial rescue mediated by the particular pattern of PrP expression in Lck-PrP mice could, in fact, point to neurobehavioral regions of importance. In particular, $\operatorname{PrP}^{\mathrm{C}}$ was not expressed in the olfactory epithelium of these mice (Fig. 5c), suggesting that the basis for the impairment was not peripheral. In addition, we observed normal odor-evoked electro-olfactogram responses from Prnp $^{-1-}$ olfactory epithelium (Supplementary Fig. 2 online). The physiological correlates underlying the impaired behavior thus appeared to reside in central structures. To streamline our investigation, we restricted our subsequent experiments to the use of the B6129 wild type, the Zürich I Prnp ${ }^{-/-}$line and the NSE-PrP transgenic line (Fig. 4e-f).

\section{Altered behavior of $\mathrm{Prnp}^{-1-}$ mice in another olfactory task}

To help ascertain whether the phenotype of the $\mathrm{Prnp}^{-/-}$mice in the cookie-finding test was indeed olfactory specific, we carried out an 

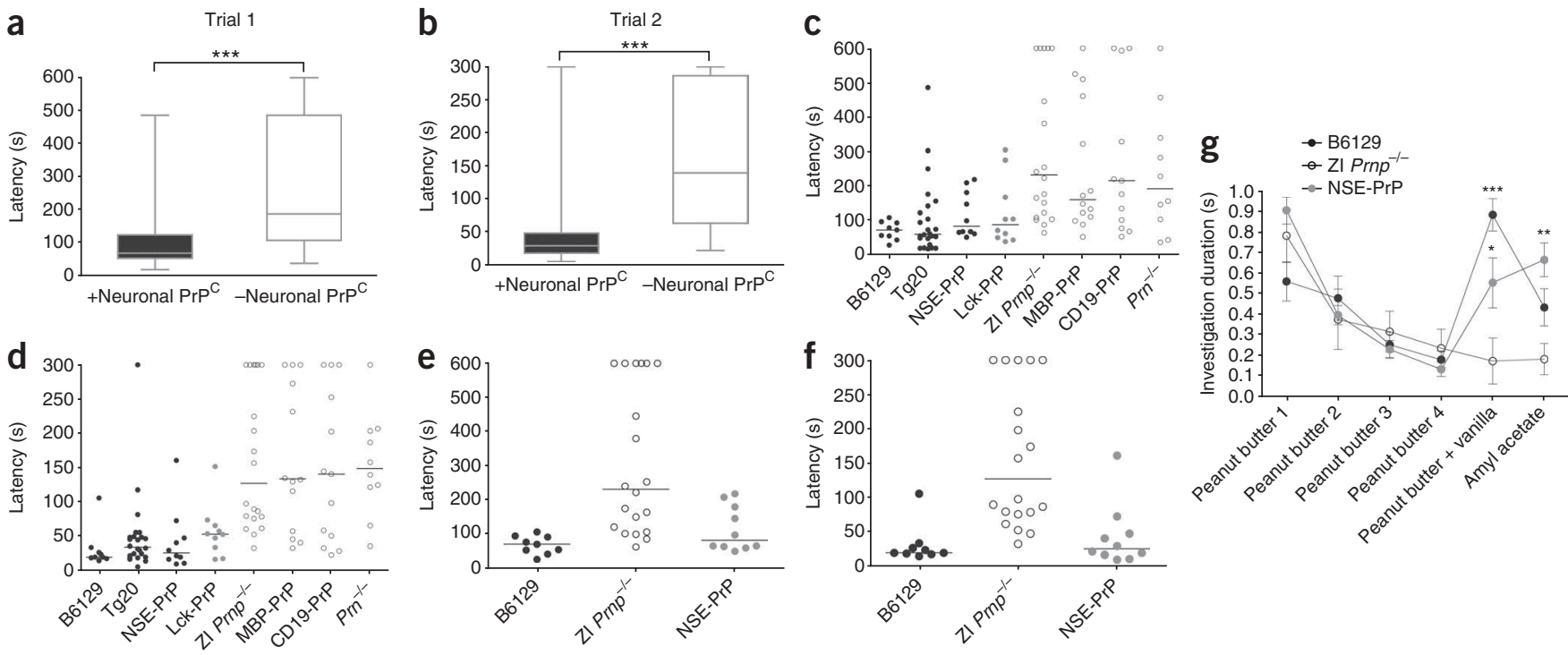

Figure 4 Neuronal PrP expression rescues the cookie-finding phenotype. (a). Trial 1 for all lines, neuronal PrPC expressers (+Neuronal PrPC: B6129, Tg20 and NSE-PrP; filled) and neuronal PrPC-deficient mice (-Neuronal PrPC: Zürich I Prnp ${ }^{-1-}$, MBP-PrP, CD19-PrP and Prnp ${ }^{-1-}$; open). For +Neuronal PrPC: minimum $=19 \mathrm{~s}$, lower quartile $=53 \mathrm{~s}$, median $=70.5 \mathrm{~s}$, upper quartile $=133 \mathrm{~s}$, maximum $=569 \mathrm{~s}$. For - Neuronal PrPC: minimum $=37 \mathrm{~s}$, lower quartile $=106.5 \mathrm{~s}$, median $=187 \mathrm{~s}$, upper quartile $=485.5 \mathrm{~s}$, $\max =600 \mathrm{~s}$. (b) Trial 2. Note reduced timescale of 5 min. For + Neuronal PrPC: minimum $=6 \mathrm{~s}$, lower quartile $=19.5 \mathrm{~s}$, median $=30 \mathrm{~s}$, upper quartile $=49 \mathrm{~s}$, maximum $=300 \mathrm{~s}$. For - Neuronal $\operatorname{PrPC}: \min =23 \mathrm{~s}$, lower quartile $=64 \mathrm{~s}$, median $=140 \mathrm{~s}$, upper quartile $=286.5 \mathrm{~s}, \max =300 \mathrm{~s}$. Individuals that failed the trial were given the conservative score of the total trial length. ${ }^{* *} P<0.001$, two-tailed Mann-Whitney test. (c,d) Breakdown by strain of data in $\mathbf{a}$ and $\mathbf{b}$, respectively. Filled dots represent strains expressing PrPC in neurons and open dots represent those that do not. Because it expressed PrPC only in some neurons, Lck-PrP (gray) was not included in either group in a and $\mathbf{b}$. Lines represent medians. (e,f) Results for the B6129, Zürich I line Prnp ${ }^{-1-}$ and NSE-PrP mouse lines, our three representative strains. (g) Altered phenotype of Zürich I line Prnp ${ }^{-1-}$ mice in the habituation-dishabituation test. All mice habituated to the first odor (peanut butter). B6129 (black) and NSE-PrP (gray) mice showed strong renewed interest in the novel odors (peanut butter + vanilla mix and amyl acetate), whereas Zürich I line Prnp ${ }^{-1-}$ mice (open dots) failed to respond to them. Error bars \pm s.e.m. ${ }^{*} P<0.05,{ }^{* *} P<0.01,{ }^{* * *} P<0.001$, two-way ANOVA, Bonferroni post test.

additional olfactory behavior test, the habituation-dishabituation assay $^{18}$. In this test, successive presentations of the same stimulus odor result in a decrease of investigatory behavior (habituation). An increase in the mouse's interest when a novel odor is presented (dishabituation) is interpreted as an ability to discriminate the difference between the two odorants. We used a peanut butter odor as the habituation odor, a mixture of peanut butter and vanilla as the first novel odor and amyl acetate as a second novel odor.

Zürich I line $\mathrm{Prnp}^{-1-}$ mice habituated to the first odor similar to controls (B6129 and NSE-PrP). However, although the controls showed increased interest in the novel odors, Prn $^{-1-}$ mice did not, indicating altered olfactory behavior (Fig. 4g). Together with the results of the cookie-finding test, this result strongly suggests that the phenotype was indeed olfactory specific.

\section{Figure 5 Lck-PrP transgenic mice express some neuronal PrPC}

(a-d) Fluorescent in situ hybridization for detection of Prnp transcripts in the olfactory bulb and cerebellum of transgenic Lck-PrP mice (a-c) and CD19PrP mice (d). Left, signal from antisense Prnp probe. Right, negative control sense probes. The Prnp probe used here was such that it only recognized wild-type Prnp transcripts and not the truncated Prnp transcript that is produced from the Zürich I Prnp knockout allele. All slides were detected over an equal amount of time. Prnp was expressed in cells of the olfactory bulb in Lck-PrP mice (a). From left to right, arrows point to examples of a Prnp-positive cell in the external plexiform layer, a mitral cell and granule cells. Prnp expression in the cerebellum of Lck-PrP mice (b). Arrow points to an example of a Prnp-positive cell in the molecular layer. Some Purkinje cells and granule cells are also labeled. Lck-PrP mice do not express Prnp in the olfactory epithelium (c). Prnp was not expressed in the olfactory bulb of CD19-PrP mice (d). The low signal that can be observed is a result of the background staining. Scale bar represents $100 \mu \mathrm{m}$.

\section{Altered responses to odor input in Prnp ${ }^{-1}$ olfactory bulb}

We focused on the electrophysiological properties of the olfactory bulb circuitry because the olfactory bulb is the first brain area to process olfactory information and the behaviorally rescued Lck-PrP mice expressed $\mathrm{PrP}^{\mathrm{C}}$ in neurons of the olfactory bulb. We recorded local field potentials (LFPs, Fig. 6) from this area because they reflect the average current flow from synaptic and spiking activity around the

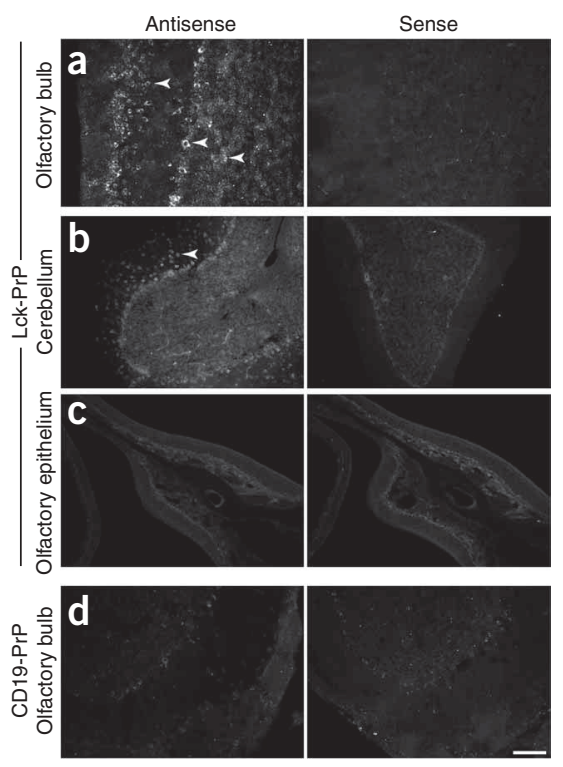


a
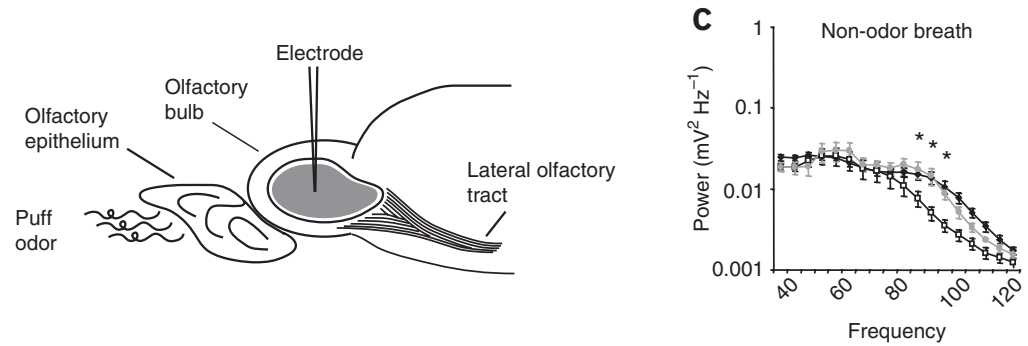

b
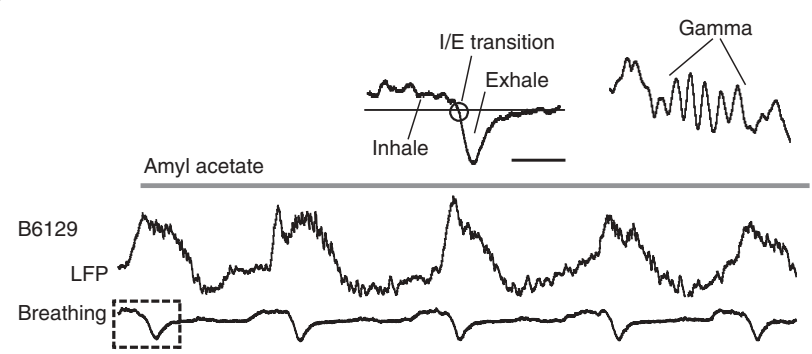

$\operatorname{Prnp}^{-/-}$

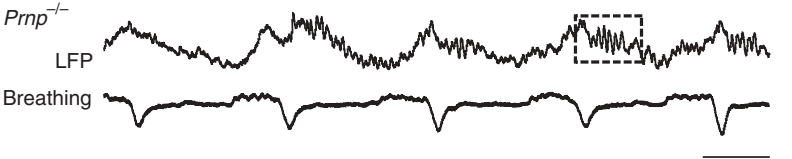

e
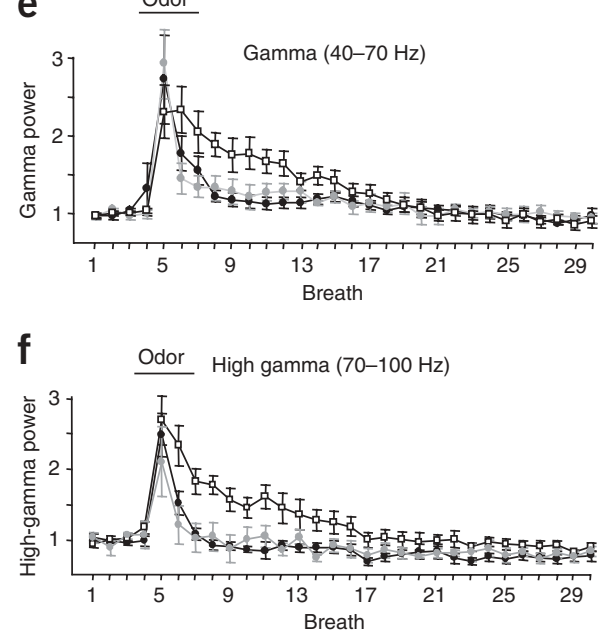
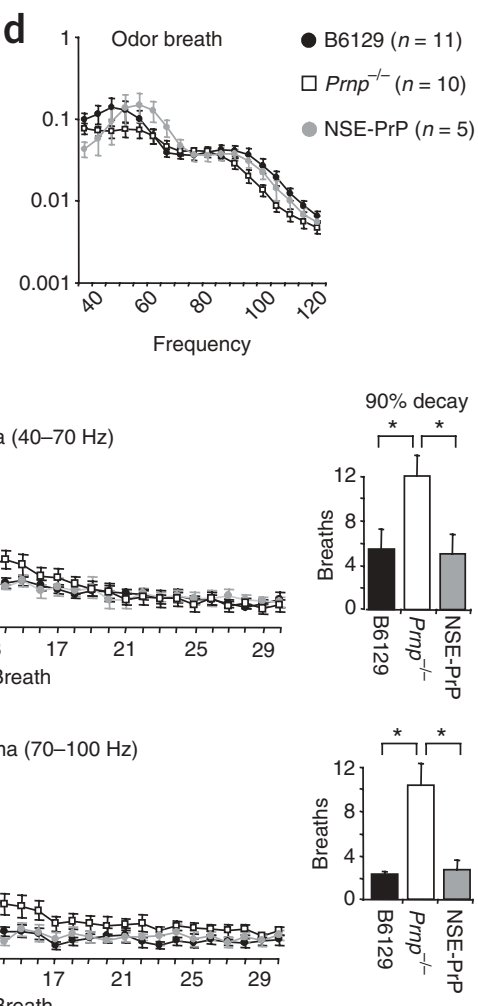

Figure 6 Power of LFPs and duration of the odor response in Prnp ${ }^{-1-}$ mice. (a) LFPs were measured in vivo from the granule cell layer in the main olfactory bulb of anesthetized mice. (b) Example LFP traces from a B6129 mouse (top) and a Prnp ${ }^{-1-}$ mouse (bottom) with corresponding breathing traces. Odor presentation was triggered by the first inhalation/exhalation transition (I/E, circle in left inset), but the odor was not detected until the following inhalation. Right inset, example of gamma-range oscillations. (c) Average power spectra of a non-odor breath from wild-type (B6129, $n=11)$, PrP knockout (Prnp ${ }^{-/}$, $n=10$ ) and neuronal PrP-expressing transgenic (NSE-PrP, $n=5$ ) mice. The power of high-gamma oscillations was significantly lower in PrP knockouts compared with both control strains. (d) In an odor-containing breath, the power of all frequencies increased in all groups. (e) The power of gamma oscillations in each breath is plotted as fold change from baseline for 30 breaths around a 2-s pulse of amyl acetate. Prnp ${ }^{-1}$ mice had an extended oscillatory response to odor in the gamma frequency band, as indicated by the time (in number of breaths) for the response to decay to $90 \%$ of its peak. (f) High-gamma oscillations in the PrP knockout also showed a significantly longer decay compared with both control strains. ${ }^{*} P<0.05$ using one-way ANOVA with post hoc PLSD. Scale bars represent $200 \mathrm{~ms}$ in $\mathbf{b}$ and $50 \mathrm{~ms}$ in inset.

recording site (Fig. 6a). Furthermore, as various frequencies of LFP oscillations specifically reflect different processes, an LFP signal simultaneously assays different types of physiological events. For example, gamma oscillations in anesthetized mice $(40-100 \mathrm{~Hz})$ reflect activity originating from a specific synapse between output neurons (mitral cells) and interneurons (granule cells) called the dendrodendritic synapse ${ }^{19,20}$.

In the olfactory bulb of anesthetized mice, LFP oscillations are coupled to the breathing cycle, allowing us to use breaths as a measure of time (Fig. 6b). We measured the power of LFP oscillations at frequencies ranging from $2-120 \mathrm{~Hz}$ over a sequence of breaths surrounding odor stimulation. We did not find alterations at beta $(10-40 \mathrm{~Hz})$ and delta frequencies (breathing rate, 2-3 Hz; data not shown), and so we focused our analysis on gamma $(40-70 \mathrm{~Hz})$ and high-gamma (70-100 Hz) oscillations.

During normal (odorless) respiration, Prnp ${ }^{-/-}$animals showed significantly lower power than B6129 and NSE-PrP control mice at $88 \mathrm{~Hz}$ (mean power in $10^{-3} \mathrm{mV}^{2} \mathrm{~Hz}^{-1}$; Prnp ${ }^{-/-}$, $9.01 \pm 2.11$; B6129, $18.80 \pm 2.96$; NSE-PrP, $22.1 \pm 5.57$; ANOVA, $P<0.05$; Fig. $6 \mathrm{c}), 93 \mathrm{~Hz}$ $\left(\right.$ Prnp $^{-1-}, 5.81 \pm 1.17$; B6129, $17.0 \pm 3.05$; NSE-PrP, $18.0 \pm 4.56$; ANOVA, $P<0.05)$ and $98 \mathrm{~Hz}\left(\right.$ Prn $^{-1-}, 3.99 \pm 0.73$; B6129, $12.80 \pm$ 2.32; NSE-PrP, $10.50 \pm 1.92$; ANOVA, $P<0.05)$. Similar analysis of the first breath of odor showed an increase in the power of oscillations in gamma and high-gamma compared with odorless respiration but without any significant differences between the groups (Fig. 6d). Analysis with finer temporal resolution was necessary to resolve any differences (Fig. 7).

Plotting the average band power for every breath allowed us to observe changes in the kinetics of the odor response. Odor stimulation elicited a strong response in both gamma (Fig. 6e) and high-gamma (Fig. 6f) bands, visible as a sharp increase in power followed by a slow decay. In $P r n p^{-/}$mice, this decay occurred over a significantly larger number of breaths than in the control group for both gamma-band oscillations (decay time in mean number of breaths: Prnp $^{-1-}, 12.0 \pm 1.8$; B6129, $5.5 \pm 1.8$; NSE-PrP, $5.0 \pm 1.7$; ANOVA, $P<0.05$; Fig. 6e) and high-gamma oscillations $\left(\right.$ Prnp $^{-1-}, 10.0 \pm 1.9$; B6129, $2.2 \pm 0.3$; NSEPrP, $2.6 \pm 0.8$; ANOVA, $P<0.001$; Fig. 6f). Together, the lower power and sustained duration of high-frequency oscillations in the $P r n p^{-1-}$ mice suggested that the temporal structure of oscillations in a single breath might also be altered.

\section{LFP oscillations poorly timed to breathing in Prnp $^{-1-}$ mice}

To better understand the oscillatory phenotype, we further analyzed our LFP data to measure the emergence and extinction of LFP oscillations in a breathing cycle. Gamma oscillations in the granule cell layer of the olfactory bulb emerged during exhalation and were 


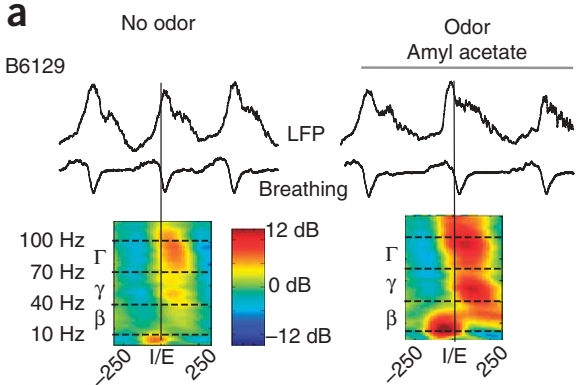

b

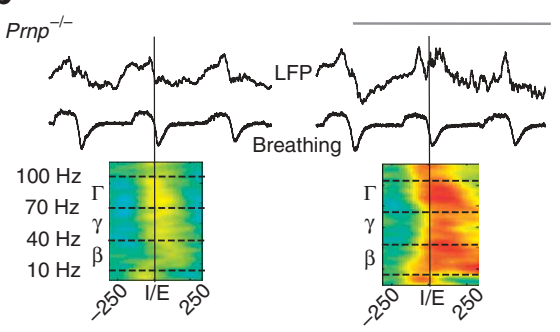

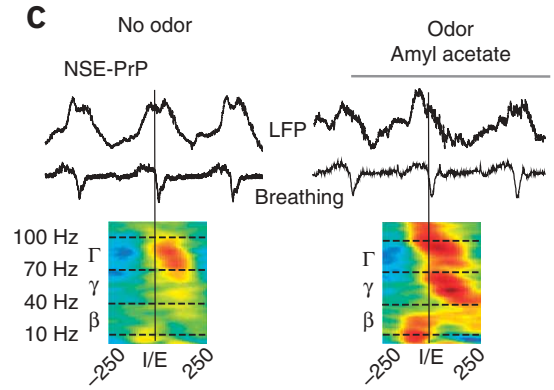

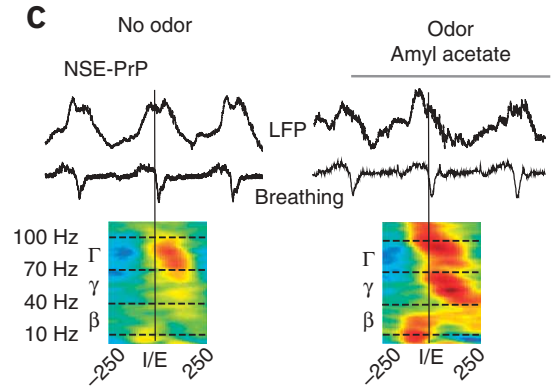

d

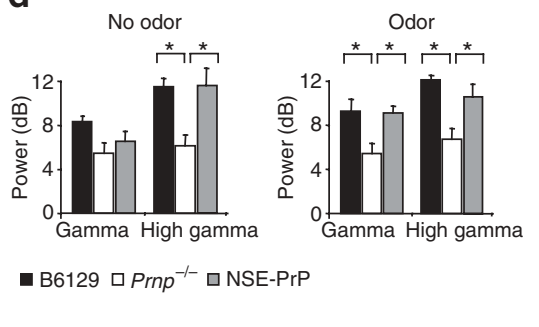

Figure 7 High-frequency oscillations in PrP knockouts are dampened in the course of a single breath. Example waveforms from single mice demonstrating how band power in high-gamma $(\Gamma, 70-100 \mathrm{~Hz})$, gamma $(\gamma, 40-70 \mathrm{~Hz})$ and beta $(\beta, 10-40 \mathrm{~Hz})$ frequencies changed around the point at which a mouse began to exhale (I/E transition, the midline of the spectrograms as marked by vertical lines, units in $\mathrm{ms}$ ). The left example is a breath without odor stimulation and the right contains the first inhalation of an odor pulse. Below each LFP and breathing waveform is the averaged spectrogram from the entire group, corresponding to breath 1 and breath 5 (dashed boxes in Supplementary Fig. 3). (a-c) B6129, (a) $\mathrm{Prnp}^{-1-}$ (b) and NSE-PrP (c) mice each showed similarly structured oscillatory patterns around a non-odor breath and an odor breath. (d) However, the difference between the band-averaged peak and subsequent trough of spectral power indicate that $P r n p^{--}$mice have less change in the highgamma band and less change during odor presentation in the gamma band. ${ }^{*} P<0.05$ using one-way ANOVA with post hoc PLSD.

extinguished shortly after (Fig. 7a-c). To our surprise, the total range of oscillatory power during a breath was smaller in the $\operatorname{Prnp}^{-1-}$ mice (Fig. 7b) compared with B6129 and NSE-PrP mice (Fig. 7a,c). Furthermore, the distribution of oscillatory power in the $\mathrm{Prnp}^{-/-}$ mice was temporally diffuse across an odor breath (Fig. 7b), an alteration that was sustained in a series of breaths following odor exposure (Supplementary Fig. 3 online).

We quantified the range of oscillatory power in a non-odor and an odor-containing breath (Fig. 7 and Supplementary Fig. 3) by taking the difference between the peak of power and the following trough. In a non-odor breath, the change in power of high-gamma oscillations in
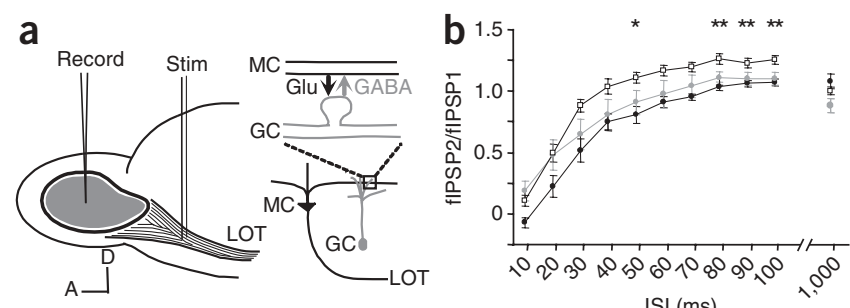

ISI (ms)
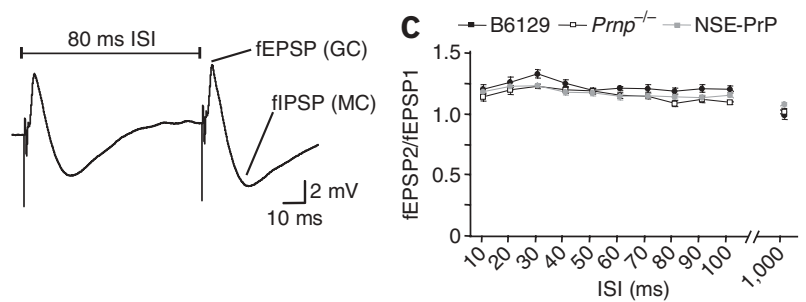

Figure 8 Paired-pulse synaptic plasticity of field potentials in the GCL after LOT stimulation. (a) Top, diagram illustrating the stimulation procedure. GC, granule cell; Glu, glutamate; LOT, lateral olfactory tract; MC, mitral cell. Middle, example trace following LOT paired-pulse stimulation $(80 \mathrm{~ms}$ interstimulus interval, ISI). (b) Paired-pulse ratio of the evoked negative potential corresponding to mitral cell fIPSP. ** indicates significant differences between both control groups and Prnp ${ }^{-1-}$ (one-way ANOVA, $P<0.05$ ); * indicates significance from B6129 (one-way ANOVA with post hoc PLSD, $P<0.05$ ). (c) Paired-pulse ratio of the evoked positive potential, corresponding to granule cell fEPSP for B6129 (filled black dots, $n=7$ ), Prnp $^{-1-}$ (open dots, $n=9$ ) and NSE-PrP (filled gray dots, $n=10$ ) mice. the Prnp ${ }^{-/-}$mice was reduced compared with B6129 and NSE-PrP mice (mean change in power $(\mathrm{dB}):$ Prnp $^{-1-}, 6.5 \pm 0.9$; B6129, $11.5 \pm 0.8$; NSE-PrP, $11.6 \pm 1.5$; Fig. 7d). Similarly, in an odor-containing breath, both gamma and high-gamma oscillations showed less change in power in Prnp $^{-/-}$mice $\left(\right.$Prnp $^{-/-}, 5.9 \pm 0.9 ;$ B6129, $9.7 \pm 1.1$; NSE-PrP, 9.5 \pm 0.6 ; Fig. 7d).

Oscillations at these high-frequency bands (gamma and high gamma) are believed to result from activity at the dendrodendritic synapse $^{19,20}$. The observed alterations in both power and timing suggested that the properties of the dendrodendritic synapse might be affected in the $\operatorname{Prnp}^{-1-}$ mice.

\section{Altered paired-pulse plasticity of dendrodendritic synapse}

We next examined the Prnp ${ }^{-1-}$ dendrodendritic synapse for changes that could underlie the observed behavioral phenotypes. We focused on the short-term plasticity of this synapse, as our LFP results suggested that $\operatorname{Prnp}^{-/-}$mice might have disrupted synchronization between breathing and oscillations, perhaps reflecting altered facilitation or depression of this synapse. We therefore carried out paired-pulse stimulation of the synapse by antidromically exciting mitral cells from their axon bundle in the lateral olfactory tract (LOT) (Fig. 8a). This stimulation procedure produces distinct field potentials corresponding to granule cell excitation (field excitatory postsynaptic potentials, fEPSPs) followed by mitral cell inhibition ${ }^{21,22}$ (field inhibitory postsynaptic potentials, fIPSPs; Fig. 8a).

In $\mathrm{Prnp}^{-/-}$mice, reciprocal inhibition of mitral cells (fIPSP) showed unusual facilitation over a range of interstimulus intervals (Fig. 8b). B6129 and NSE-PrP mice had a significantly facilitated paired-pulse ratio from the $\mathrm{Prnp}^{-/-}$mice at intervals between 80 and $100 \mathrm{~ms}$, and B6129 mice also showed a significantly different ratio at $50 \mathrm{~ms}$ (ANOVA with Fisher's PLSD, $P<0.05$ ). Notably, facilitation of the fIPSP in the Prnp ${ }^{-1-}$ mice was not accompanied by any differences in the plasticity of the granule cell fEPSPs (Fig. 8c).

\section{DISCUSSION}

Here we describe a previously unknown olfactory behavioral phenotype of $\mathrm{Prnp}^{-/-}$mice and physiological alterations in their olfactory bulb. The cookie-finding phenotype was manifest in three Prnp $p^{-1-}$ lines on alternate genetic backgrounds, which is strong evidence of its 
dependence on $\operatorname{PrP}^{\mathrm{C}}$ rather than on other genetic factors. PrP knockouts also showed altered behavior in the habituation-dishabituation task, suggesting that the phenotype was probably olfactory specific. $\mathrm{Prnp}^{-/-}$mice had widespread alterations of oscillatory activity in the olfactory bulb and altered paired-pulse plasticity at the dendrodendritic synapse. Notably, both the behavioral and electrophysiological phenotypes could be rescued by neuronal $\operatorname{PrP}^{\mathrm{C}}$ expression. These data suggest a critical role for $\operatorname{PrP}^{\mathrm{C}}$ in the normal processing of sensory information by the olfactory system.

$\mathrm{PrnP}^{-1-}$ mouse cookie-finding behavior markedly resembled that of the anosmic Adcy $3^{-1-}$ mice; however, $\mathrm{Prnp}^{-1-}$ mice are clearly not anosmic. Indeed, no aspect of $\mathrm{Prnp}^{-1-}$ mouse survival suggested that they might harbor a deficit in an odor-guided task. Anosmic pups have an $80 \%$ neonatal fatality rate as a result of difficulty in suckling at birth and inadequate maternal care, and those that survive have low body weight during their first 3 months ${ }^{14}$. In contrast, Prnp $^{-/}$mice have healthy litters of average size ( $\sim 6-9$ pups per litter) that grow to normal body weights. The lack of outward signs of anosmia is probably a reason why olfactory tasks have been overlooked in previous behavioral characterizations of $\mathrm{Prnp}^{-/-}$mice.

The behavioral impairment that we detected in PrP knockouts did not originate in the periphery. This is supported by the normal appearance of odor-evoked electro-olfactogram responses from $P_{P r n}{ }^{-/}$olfactory epithelium and by the rescued behavior of Lck-PrP mice that do not express $\mathrm{PrP}^{\mathrm{C}}$ in their olfactory sensory neurons but do in subsets of central neurons, including in the olfactory bulb. Therefore, the $\mathrm{Prnp}^{-/-}$behavior deficit probably arises from alterations in central processing events in the olfactory bulb and/or higher centers.

One initial concern regarding the behavioral phenotype was the mixed background of the Zürich I Prnp ${ }^{-1-}$ mice. Any phenotype of Zürich I knockout mice could be the result of genes with a 129 origin that are linked to Prnp rather than to the knockout allele itself. The marked impairments that we had detected thus necessitated cautious interpretation.

We confirmed the phenotype of the Zürich I knockouts through two strategies: testing alternate $\mathrm{Prnp}^{-1-}$ mouse lines with different genetic backgrounds (B6 congenic (Nagasaki) and 129 isogenic (Edinburgh)) and using transgenic lines on the Zürich I background that express $\mathrm{PrP}^{\mathrm{C}}$ in specific cell subtypes.

The use of multiple knockout lines illustrated how genetic background can modulate phenotypic severity. For example, although the Nagasaki knockouts scored consistently slower latencies than their wild-type B6 counterparts, they were, on average, faster than the Zürich I line knockouts. Furthermore, no Nagasaki individual failed the test whereas a third of Zürich I line knockouts failed each trial. A predominantly B6 background thus appeared to attenuate the phenotype, although no difference was apparent between wild-type B6 and 129 strains, perhaps as a result of a floor effect, with all wild types achieving an unsurpassable threshold of rapidity.

The transgenic approach demonstrated that the phenotype was neuronal specific. NSE-PrP and Lck-PrP mice were rescued, whereas MBP-PrP and CD19-PrP mice were not. Additional tested lines all segregated in a similar fashion, according to whether or not they expressed neuronal $\operatorname{Pr}^{\mathrm{C}}$. Perhaps most notably, the rescued behavior of the NSE-PrP mice indicates that the $\operatorname{Prnp}^{-/-}$phenotype was indeed the result of the absence of $\operatorname{PrP}$ and not of genes in the vicinity of Prnp, as the introduction of the $\operatorname{PrP}$ transgene alone sufficed to mediate the rescue.

Thus, although the phenotype was attributable to lack of PrP, its olfactory specificity remained uncertain because of the behavioral complexity of the cookie-finding test. Food consumption and body weight of $\mathrm{Prnp}^{-/-}$mice appeared to be no different from controls, allowing us to rule out any possible alterations in metabolism or appetite. Knockouts performed similarly to wild types in a control version of the experiment, in which the food stimulus was no longer concealed beneath the bedding. Knockouts were therefore fully capable of navigating the test cage and locating the visible cookie, suggesting the deficit in the cookie-finding test was thus neither locomotor nor exploratory. Furthermore, Prnp $^{-/-}$mice have been documented to perform normally in tests using extensive locomotor skills, such as the Morris water maze ${ }^{1}$. Notably, in an additional olfactory assay, $\mathrm{Prnp}^{-1-}$ mice also showed altered behavior, failing to react to a novel odor that was discriminable by NSE-PrP and B6129 mice. Together, the phenotypes in the cookie-finding and the habituation-dishabituation tests pointed to an olfactory-specific phenotype.

We therefore focused our follow-up investigation on the olfactory bulb, as it contains the initial synapse of the olfactory system and the first circuit to integrate sensory and higher cortical information. We observed disruptions in LFP oscillations and in the plasticity of the dendrodendritic synapse, either or both of which could contribute to the $\operatorname{Prnp}^{-1-}$ behavioral phenotype.

Oscillatory LFPs may act to organize information flow in the olfactory system ${ }^{23,24}$ by constraining the timing of mitral cell action potentials ${ }^{25}$. In addition, gamma oscillations are specifically implicated in behavioral performance in olfactory tasks ${ }^{26-28}$. Therefore, alterations in oscillatory timing during odor exposure may perturb olfactory bulb output to higher centers by disrupting how information is packaged in a breathing cycle.

Altering the dendrodendritic synapse may have multiple functional consequences. This synapse may mediate lateral inhibition between ensembles of mitral cells and may be critical for olfactory discrimination $^{29,30}$. In addition, because granule cells receive convergent information onto their proximal dendritic arbor from multiple higher brain $\mathrm{areas}^{31}$, disruption of the dendrodendritic synapse may alter the transmission of centrifugal modulation to olfactory bulb mitral cells.

High-frequency oscillations in the olfactory bulb (gamma and high gamma) have been shown in vitro to result from the rapid and reciprocal interactions between granule and mitral cells across the dendrodendritic synapse ${ }^{19,20}$. Therefore, our data could imply that increased facilitation of the mitral cell IPSP following repetitive spiking decreases the dynamic range and increases the duration of gamma oscillations across the boundaries of a breath. Unfortunately, not enough is currently known about how changes in basic parameters of synaptic physiology manifest themselves on the scale of local field potentials in vivo. Thus, although both oscillatory and synaptic effects could be reversed by neuronal $\operatorname{PrP}^{\mathrm{C}}$ expression, we cannot claim a causal link between these findings.

Other physiological alterations reported in $\mathrm{Prnp}^{-/-}$mice include altered GABA-mediated synaptic currents in CA1 neurons of the hippocampus ${ }^{32}$ (but see ref. 33), altered long-term and post-tetanic potentiation ${ }^{34}$, and altered paired-pulse plasticity in the dentate gyrus ${ }^{6}$. Given that $\mathrm{PrP}^{\mathrm{C}}$ is membrane associated, synaptically enriched ${ }^{35}$ and present in the external plexiform layer of the olfactory bulb ${ }^{10}, \operatorname{PrP}^{\mathrm{C}}$ may function as a member of the synaptic machinery in the olfactory bulb and the hippocampus. Putative molecular partners of $\operatorname{PrP}^{\mathrm{C}}$ include synaptic molecules such as synapsin $\mathrm{Ib}^{36}$.

We observed that mitral cells received facilitated inhibition in $\mathrm{Prnp}^{-/-}$ mice. This facilitation could result from either pre- and/or postsynaptic changes to the dendrodendritic synapse. Future work should determine the precise synaptic localization of the $\mathrm{PrP}^{\mathrm{C}}$ protein and its biochemical interactions with synaptic machinery. It also remains to be seen whether higher centers involved in olfactory processing and 
memory are similarly affected by lack of $\mathrm{PrP}^{\mathrm{C}}$ or whether analogous synaptic alterations can be detected in other brain regions. Furthermore, the transgenic rescue strategy that we used cannot indicate whether the observed phenotypes are the result of developmental changes in olfactory circuitry. Future use of conditional strategies using tissue-specific promoters may allow a more precise dissection of the physiological and behavioral importance of $\mathrm{PrP}^{\mathrm{C}}$ for olfactory processing.

Although the physiological function of $\mathrm{PrP}^{\mathrm{C}}$ is unknown, its role in the pathogenesis of prion diseases has been established beyond a reasonable doubt ${ }^{2}$. The scarcity of any marked pathological phenotypes, particularly in the nervous system, of Prnp-ablated mice was originally taken as evidence that loss-of-function phenomena are not important in prion diseases ${ }^{37}$. Our findings suggest that a more nuanced view may be appropriate and that at least some components of the neurological phenotype of prion infections may be assigned to the malfunction of $\mathrm{PrP}^{\mathrm{C}}$-dependent neuronal events.

\section{METHODS}

Animals. All of the PrP-related knockout and transgenic animals shown in Table 1 were provided by A. Aguzzi (University Hospital of Zürich). Because the Zürich I Prnp ${ }^{-/-}$mice $^{1}$ are on a mixed C57BL6/J (B6) and 129/SvEv (129) genetic background and lack wild-type littermates, we used the F1 hybrid strain of B6 and 129 (B6129) as the wild-type control. Adcy $3^{-/-}$mice, also on a mixed B6 and 129 background, were obtained from D. Storm (University of Washington $)^{14}$. Use of the Edinburgh Prnp $^{-/-}$mice and wild-type littermates ${ }^{38}$ was kindly permitted by the Institute for Animal Health and J. Manson (University of Edinburgh). All animals were housed at either Columbia University or the University Hospital of Zürich in accordance with institutional requirements for animal care. The Columbia University Institutional Animal Care and Use Committee and the Cantonal Animal Experimentation Committee (Zürich) reviewed and approved these experiments.

Cookie finding-behavior test. In this test, a cookie was buried under the cage bedding so as to offer a purely olfactory cue, and the time taken by a mouse to retrieve the cookie was recorded.

Habituation-dishabituation test. The initial interest in an odor presented several times in succession is expected to decrease with each presentation as the animal habituates to the odor. On the fifth presentation, a novel odor is presented. The novelty of the odor should induce an increase in the animal's investigation time and this is interpreted as an ability to discriminate between odors 1 and 2 .

Odor delivery. A custom-made olfactometer was adapted from a previous design ${ }^{39}$. Compressed air was humidified and passed by the mouse's nose. Odor puffs $(2 \mathrm{~s})$ were diverted into the carrier stream. For every mouse, odor was delivered at least seven times, spaced apart with pulses of solvent headspace.

Electrophysiology recordings. The anesthetized mouse's nose was inserted into an air-tight gas mask through which humidified air from the olfactometer was passed. Two craniotomies were performed for insertion of a custom-made tungsten recording electrode $\mathrm{e}^{40}$ into the granule cell layer of the main olfactory bulb, and a custom-made bipolar tungsten stimulating electrode into the LOT. Breathing was monitored with a piezoelectric force-transducer (Stoelting); this signal was used to reliably trigger odor delivery at the transition of inhalation to exhalation.

LFP signal processing and analysis. All signal processing was done off-line using custom-written scripts in Spike2, and in Matlab (Mathworks) using a combination of custom-written scripts and eeglab $6.01 \mathrm{~b}^{41}$.

Statistics. For our behavior experiments, statistical analysis was performed using Prism software (GraphPad). Cookie-finding data were analyzed using nonparametric statistics, as the latencies to retrieve the cookie did not follow a normal distribution. The Mann-Whitney test was used for comparison between two groups. For comparison between more than two groups, we used the
Kruskal-Wallis one-way ANOVA followed by Dunn's post hoc analysis when a significant overall main effect was found $(P<0.05)$. Habituationdishabituation data were analyzed using a one-way ANOVA followed by the Bonferroni test when a significant main effect was found $(P<0.05)$. For our physiology experiments, statistical analysis was carried out using StatView 5.0 (SAS Institute). Data from three experimental groups was compared using a one-way ANOVA test followed by post hoc analysis using Fisher's PLSD when a significant overall main effect was found $(P<0.05)$.

For full details, see Supplementary Methods online.

Note: Supplementary information is available on the Nature Neuroscience website.

\section{ACKNOWLEDGMENTS}

The authors thank members of the Aguzzi laboratory for their assistance, especially G. Miele and P. Schwartz. We also thank J. Manson for the use of the Edinburgh Prnp ${ }^{-1-}$ line, D.-J. Zou and D. Kelley for helpful comments on the behavioral experiments, and J. Gordon for valuable discussions on the electrophysiology data. This work was supported by grants from the National Institute on Deafness and Other Communication Disorders (S.F., C.E.L.P., M.T.V., B.T.S. and A.T.C.). C.E.L.P. also received a Short-Term Fellowship from the European Molecular Biology Organization. A.A. and M.P. were supported by grants from the European Community and the Swiss National Science Foundation.

\section{AUTHOR CONTRIBUTIONS}

C.E.L.P., A.T.C., M.P., A.A. and S.F. designed the behavior experiments. M.T.V., B.T.S. and S.F. conceived the electrophysiology experiments. C.E.L.P., A.T.C. and M.P. carried out the cookie-finding behavior experiments and C.E.L.P. and M.T.V. performed the habituation-dishabituation test. C.E.L.P. analyzed all of the behavior experiments and carried out the behavior control experiments. B.T.S. designed the electrophysiology setup. M.T.V. performed the electrophysiology experiments and their analysis. C.E.L.P., M.T.V. and S.F. wrote the paper. All the authors discussed the results and commented on the manuscript.

Published online at http://www.nature.com/natureneuroscience/ Reprints and permissions information is available online at http://www.nature.com/ reprintsandpermissions/

1. Bueler, H. et al. Normal development and behaviour of mice lacking the neuronal cellsurface PrP protein. Nature 356, 577-582 (1992).

2. Bueler, H. et al. Mice devoid of PrP are resistant to scrapie. Cell 73, 1339-1347 (1993).

3. Steele, A.D., Lindquist, S. \& Aguzzi, A. The prion protein knockout mouse, a phenotype under challenge. Prion 1, 83-93 (2007).

4. Tobler, I. et al. Altered circadian activity rhythms and sleep in mice devoid of prion protein. Nature 380, 639-642 (1996).

5. Tobler, I., Deboer, T. \& Fischer, M. Sleep and sleep regulation in normal and prion protein-deficient mice. J. Neurosci. 17, 1869-1879 (1997).

6. Criado, J.R. et al. Mice devoid of prion protein have cognitive deficits that are rescued by reconstitution of PrP in neurons. Neurobiol. Dis. 19, 255-265 (2005).

7. Rangel, A. et al. Enhanced susceptibility of Prnp-deficient mice to kainate-induced seizures, neuronal apoptosis and death: role of AMPA/kainate receptors. J. Neurosci. Res. 85, 2741-2755 (2007).

8. Walz, R. et al. Increased sensitivity to seizures in mice lacking cellular prion protein. Epilepsia 40, 1679-1682 (1999).

9. Ford, M.J. et al. A marked disparity between the expression of prion protein and its message by neurones of the CNS. Neuroscience 111,533-551 (2002).

10. Le Pichon, C.E. \& Firestein, S. Expression and localization of the prion protein $\operatorname{PrPC}$ in the olfactory system of the mouse. J. Comp. Neurol. 508, 487-499 (2008).

11. Kay, L.M. \& Stopfer, M. Information processing in the olfactory systems of insects and vertebrates. Semin. Cell Dev. Biol. 17, 433-442 (2006).

12. Schoppa, N.E. \& Urban, N.N. Dendritic processing within olfactory bulb circuits. Trends Neurosci. 26, 501-506 (2003).

13. Walz, A., Mombaerts, P., Greer, C.A. \& Treloar, H.B. Disrupted compartmental organization of axons and dendrites within olfactory glomeruli of mice deficient in the olfactory cell adhesion molecule, OCAM. Mol. Cell. Neurosci. 32, 1-14 (2006).

14. Wong, S.T. et al. Disruption of the type III adenylyl cyclase gene leads to peripheral and behavioral anosmia in transgenic mice. Neuron 27, 487-497 (2000).

15. Trinh, K. \& Storm, D.R. Vomeronasal organ detects odorants in absence of signaling through main olfactory epithelium. Nat. Neurosci. 6, 519-525 (2003).

16. Moore, R.C. et al. Ataxia in prion protein (PrP)-deficient mice is associated with upregulation of the novel PrP-like protein doppel. J. Mol. Biol. 292, 797-817 (1999).

17. Omri, B. et al. The Lck tyrosine kinase is expressed in brain neurons. J. Neurochem. 67, 1360-1364 (1996).

18. Schellinck, H.M., Price, S.R. \& Wong, M.J. Using ethologically relevant tasks to study olfactory discrimination in rodents. in Chemical Signals in Vertebrates // (eds. Hurst, J.L., Beynon, R.J., Roberts, S.C. \& Wyatt, T.D.) (Springer, New York, 2008). 
19. Lagier, S. et al. GABAergic inhibition at dendrodendritic synapses tunes gamma oscillations in the olfactory bulb. Proc. Natl. Acad. Sci. USA 104, 7259-7264 (2007).

20. Schoppa, N.E. Synchronization of olfactory bulb mitral cells by precisely timed inhibitory inputs. Neuron 49, 271-283 (2006).

21. Mori, K. \& Takagi, S.F. An intracellular study of dendrodendritic inhibitory synapses on mitral cells in the rabbit olfactory bulb. J. Physiol. (Lond.) 279, 569-588 (1978).

22. Nicoll, R.A. Inhibitory mechanisms in the rabbit olfactory bulb: dendrodendritic mechanisms. Brain Res. 14, 157-172 (1969).

23. Lledo, P.M. \& Lagier, S. Adjusting neurophysiological computations in the adult olfactory bulb. Semin. Cell Dev. Biol. 17, 443-453 (2006).

24. Stopfer, M. Olfactory processing: massive convergence onto sparse codes. Curr. Biol. 17, R363-R364 (2007).

25. Kashiwadani, H., Sasaki, Y.F., Uchida, N. \& Mori, K. Synchronized oscillatory discharges of mitral/tufted cells with different molecular receptive ranges in the rabbit olfactory bulb. J. Neurophysiol. 82, 1786-1792 (1999).

26. Beshel, J., Kopell, N. \& Kay, L.M. Olfactory bulb gamma oscillations are enhanced with task demands. J. Neurosci. 27, 8358-8365 (2007).

27. Brown, S.L., Joseph, J. \& Stopfer, M. Encoding a temporally structured stimulus with a temporally structured neural representation. Nat. Neurosci. 8, 1568-1576 (2005).

28. Nusser, Z., Kay, L.M., Laurent, G., Homanics, G.E. \& Mody, I. Disruption of GABA(A) receptors on GABAergic interneurons leads to increased oscillatory power in the olfactory bulb network. J. Neurophysiol. 86, 2823-2833 (2001).

29. Urban, N.N. Lateral inhibition in the olfactory bulb and in olfaction. Physiol. Behav. 77, 607-612 (2002)

30. Yokoi, M., Mori, K. \& Nakanishi, S. Refinement of odor molecule tuning by dendrodendritic synaptic inhibition in the olfactory bulb. Proc. Natl. Acad. Sci. USA 92, 3371-3375 (1995).

31. Shepherd, G.M. The Synpatic Organization of the Brain (Oxford University Press, New York, 2003).

32. Collinge, J. et al. Prion protein is necessary for normal synaptic function. Nature $\mathbf{3 7 0}$, 295-297 (1994)

33. Lledo, P.M., Tremblay, P., DeArmond, S.J., Prusiner, S.B. \& Nicoll, R.A. Mice deficient for prion protein exhibit normal neuronal excitability and synaptic transmission in the hippocampus. Proc. Natl. Acad. Sci. USA 93, 2403-2407 (1996).
34. Curtis, J., Errington, M., Bliss, T., Voss, K. \& MacLeod, N. Age-dependent loss of PTP and LTP in the hippocampus of PrP-null mice. Neurobiol. Dis. 13, 55-62 (2003).

35. Fournier, J.G., Escaig-Haye, F. \& Grigoriev, V. Ultrastructural localization of prion proteins: physiological and pathological implications. Microsc. Res. Tech. 50, 76-88 (2000).

36. Spielhaupter, C. \& Schatzl, H.M. PrPC directly interacts with proteins involved in signaling pathways. J. Biol. Chem. 276, 44604-44612 (2001).

37. Aguzzi, A. \& Polymenidou, M. Mammalian prion biology: one century of evolving concepts. Cel/ 116, 313-327 (2004).

38. Manson, J.C. et al. 129/Ola mice carrying a null mutation in PrP that abolishes mRNA production are developmentally normal. Mol. Neurobiol. 8, 121-127 (1994).

39. Lorig, T.S., Elmes, D.G., Zald, D.H. \& Pardo, J.V. A computer-controlled olfactometer for fMRI and electrophysiological studies of olfaction. Behav. Res. Methods Instrum. Comput. 31, 370-375 (1999).

40. Hubel, D.H. Tungsten microelectrode for recording from single units. Science $\mathbf{1 2 5}$ 549-550 (1957).

41. Delorme, A. \& Makeig, S. EEGLAB: an open source toolbox for analysis of single-tria EEG dynamics including independent component analysis. J. Neurosci. Methods 134 9-21 (2004).

42. Sakaguchi, S. et al. Loss of cerebellar Purkinje cells in aged mice homozygous for a disrupted PrP gene. Nature 380, 528-531 (1996).

43. Fischer, M. et al. Prion protein (PrP) with amino-proximal deletions restoring susceptibility of PrP knockout mice to scrapie. EMBO J. 15, 1255-1264 (1996).

44. Radovanovic, I. et al. Truncated prion protein and Doppel are myelinotoxic in the absence of oligodendrocytic PrPC. J. Neurosci. 25, 4879-4888 (2005).

45. Prinz, M. et al. Intrinsic resistance of oligodendrocytes to prion infection. J. Neurosci. 24, 5974-5981 (2004).

46. Montrasio, F. et al. B lymphocyte-restricted expression of prion protein does not enable prion replication in prion protein knockout mice. Proc. Natl. Acad. Sci. USA 98 4034-4037 (2001).

47. Raeber, A.J. et al. Ectopic expression of prion protein ( $\mathrm{PrP}$ ) in $\mathrm{T}$ lymphocytes or hepatocytes of PrP knockout mice is insufficient to sustain prion replication. Proc. Natl. Acad. Sci. USA 96, 3987-3992 (1999).

48. Genoud, N. et al. Disruption of Doppel prevents neurodegeneration in mice with extensive Prnp deletions. Proc. Natl. Acad. Sci. USA 101, 4198-4203 (2004). 